\title{
Autogenous Bone Graft versus Artificial Substitutes in Cranioplasty
}

\author{
Hassan Hassan, Alaeddin Ali, Ahmad Abdalla \\ Neurosurgery Department, Assiut University, Assiut, Egypt \\ Email: h_moh_h@yahoo.com
}

How to cite this paper: Hassan, H., Ali, A. and Abdalla, A. (2019) Autogenous Bone Graft versus Artificial Substitutes in Cranioplasty. Open Journal of Modern Neurosurgery, 9, 338-355.

https://doi.org/10.4236/ojmn.2019.93032

Received: June 28, 2019

Accepted: July 28, 2019

Published: July 31, 2019

Copyright $\odot 2019$ by author(s) and Scientific Research Publishing Inc. This work is licensed under the Creative Commons Attribution International License (CC BY 4.0).

http://creativecommons.org/licenses/by/4.0/

(c) (i) Open Access

\begin{abstract}
Cranioplasty is a routine procedure in neurosurgery. However, it has a high postoperative complication rate up to $40 \%$. The lack of good prospective studies and the small number of patients who receive artificial substitutes make it difficult to choose between different materials and the decision is mostly based on subjective or economic reasons. The main goal of this study was to compare the most common complications related to the implant within the first year after implantation. Methods: This prospective randomized clinical study has been carried out on 32 patients with cranial defects of different etiologies, sites and sizes which have been operated in Assiut University Hospital from January 2016 to January 2017. The patients were randomized into two groups: Autologous and Artificial group. Each group has 16 patients. Results: The overall complication rate in autologous group was found to be (25\%) and in artificial group (37.5\%). Infection in autologous group was found in (6.25\%), in artificial group was found in (12.5\%). Bone resorption was found in (12.5\%). For epidural hematoma and wound dehiscence each has a rate of (6.25\%). Poor cosmetic result in (18.75\%) of artificial group. Conclusion: Cranioplasty is not without complications. However, good decision making, good timing and proper surgical techniques can provide excellent results. Primary titanium mesh cranioplasty should be considered especially in young adult patients with traumatic aetiology of bone defect.
\end{abstract}

\section{Keywords}

Cranioplasty, Titanium Mesh, Autogenous Bone, Bone Cement, Medpor

\section{Introduction}

Cranioplasty is defined as the surgical repair of a defect in the cranium by insertion of an object (bone or non biological materials such as metal or plastic plates) [1]. 
Repairing the cranial bone is one of the oldest neurosurgical practices dating back to ancient Egypt [2].

Replacing the cranium is not only a protective and cosmetic procedure but may also reverse the altered physiological state that occurs following craniectomy and improve electroencephalographically abnormalities, aberrations of cerebral blood flow and cerebrospinal fluid dynamics. The aim of a cranioplasty procedure is to achieve a lifelong, stable, structural reconstruction of the cranium covered by a healthy skin that eliminates the psychological problems of patients, improves the quality of life and increases social adaptation [3].

In the past, delayed cranioplasty (more than 6 months interval between craniectomy and cranioplasty) was considered the optimal timing because it showed a lower infection rate, One author reported 390 days as the mean time between craniectomy and cranioplasty in 2015 [4]. Recently, several reports recommend early cranioplasty because it was found that cranioplasty improved clinical outcomes. In the aspect of postoperative infection, multinational prospective designed study says no difference exists of the infection rates between early and delayed cranioplasty [5].

To repair the bone defect, numerous natural and artificial materials have been used by neurosurgeons, including autograft, allograft, xenograft [6], as well as artificial or synthetic materials such as titanium, polymethyl methacrylate (PMMA) and Medpor (porous polyethylene). These materials have many advantages such as mechanical strength and biocompatibility, but none of these materials is perfect cranioplasty material [7]. Neurosurgeons have been evaluating their advantages and shortages through clinical practice.

\section{Patients \& Methods}

This prospective randomized clinical study has been carried out on 32 patients with cranial defects of different etiologies, sites and sizes have been operated upon in Assiut University Hospital between January 2016 to January 2017. The patients were randomized to receive either their own bone (autologous) that had been stored in subcutaneous abdominal pocket or another (artificial) substance (titanium mesh, bone cement or medpor).

General and neurological examination has been done to all patients. The general examination included examination of the defect to determine the site and the size of the defect and to detect any signs of inflammation, and the quality of the overlying skin. Complete neurological assessment of the patients has been done with particular emphasis on the motor power. The major aspects of the examination include:

1) Mental status examination

2) Cranial Nerves

3) Muscle strength, tone and bulk

4) Reflexes

5) Coordination

6) Sensory Function 
7) Gait

Preoperative CT scans with a bone window \& 3D scan have been done for all the patients to demonstrate the defect and to detect any underlying brain pathology.

\subsection{Inclusion Criteria}

- All patients that have reconstructive surgery of cranial defects due to traumatic or lesion resection causes.

- Age older than 20 and less than 60 years with provided written informed consent.

\subsection{Exclusion Criteria}

We excluded from our work:

- Cases of cranial defects due to congenital anomalies, growing skull fractures and infections (osteomyelitis).

- Patients who were unfit for surgery.

A written informed consent in Arabic was obtained from the patients before being enrolled in the study, explaining the treatment options, possible complications and cost of different used materials. Also, the need of further studies to evaluate the post operative outcome.

Ethical approval was taken from the Institutional Review Board (IRB) of faculty of medicine, Assiut University.

\subsection{Surgical Technique}

The procedure was performed when cerebral swelling had subsided and the patient was medically stable. Following endotracheal intubation, the patient was placed on the operating table with the head supported on a head ring. A single dose of a broad-spectrum antibiotic agent was given intravenously at induction of anesthesia. The patient's hair was completely removed with a margin of at least $3 \mathrm{~cm}$ from the incision line using an appropriate hair shaver. Great care was taken to avoid skin damage. Care was taken to avoid hair contamination and to leave a gap of approximately $2 \mathrm{~cm}$ between the edge of the drapes and the incision line.

Care was taken to ensure that all surfaces were covered. Under a general anesthetic, the previous scar, if present, will be reopened and sometimes extended to allow complete exposure of the bony edges. A repair is then done using autologous bone or alloplastic substances: titanium mesh, methylmethacrylate or porous polyethylene (Medpor).

To reduce the incidence of adverse events, we used bipolar coagulation, used to relieve pressure periodically on the retracted skin flap to protect flap microcirculation and we have increased the use of subcutaneous sutures, minimizing skin stitches.

For the craniotomy flap used in 16 patients we had stored the bone flap in the 
abdominal subcutaneous tissue of the patient then reused it in a later setting again to cover the defect. Titanium mesh was used in another 8 cases. In these cases, the mesh was placed and fixed to the surrounding bone using titanium screws. Methyl methacrylate (bone cement) was used alone in 4 cases, In acrylic cranioplasty, the acrylic mixture is molded into plate and having the shape of the defect then we create several holes in the plate and apply it before hardening to fit it by hand compression to the skull edges. Continuous irrigation with saline is used to guard against the exothermic reaction. finally, Medpor was used in 4 cases.

Postoperatively: All patients were dressed daily using povidine iodine for two weeks. All patients received post-operative antibiotics in the form of the third generation cephalosporin. We used wounds drainage for 48 hours. Clinical follow up has been documented immediately post operatively, and every 3 months. It was done to assess functional and aesthetic outcome. Radiological follow up of the patients using a CT scan brain was done, 2 days after surgery and at least one time in the after visits. Lateral and postero anterior skull X-ray was obtained to assess the fixation and position of the implant when needed. CT scan has been repeated when needed. Last Clinical follow up of the patients was an average of 12 months. The data were collected \& analyzed.

Data were collected to include patient's age, sex, etiology of bone defect, time of surgical procedure, time interval between craniectomy and cranioplasty, material used in cranioplasty (autologous bone vs. artificial), and complications.

Three different aetiologies of (skull bone defect) were selected in the study. (Trauma) includes bone loss from the trauma itself and post traumatic decompressive craniectomy, (tumor) means that the first presentation of the patient was diagnosed as a brain tumor, surgical excision was done with removal partialy of the skull bone and replaced later on. Finally, (spontaneous hemorrhage) includes cases of spontaneous (non traumatic) subdural hematoma or intracerebral hematoma who underwent decompressive surgery.

Time of surgical procedure: was divided into 3 categories: $<60$ minutes, from 60 to 120 minutes, and $>120$ minutes.

Time interval between craniectomy and cranioplasty: was divided into 3 categories: $<12$ weeks interval (early cranioplasty), between $12-24$ weeks and $>24$ weeks (delayed cranioplasty).

Complications include all infections, wound breakdowns, cases of significant bone resorption, epidural hematoma and poor cosmetic result. Seizures were excluded as complications because many patients were noted to have an underlying seizure disorder prior to cranioplasty.

\subsection{Outcome Measures}

\subsubsection{Primary Outcome Measure: Implant Failure Requiring Reoperation}

Implant failure requiring reoperation could have been due to infection (defined as an infected cranioplasty that required removal of the implant and systemic 
antibiotic therapy) or autologous bone flap resorption (assessed using CT scans following the immediate autologous cranioplasty and at 12 months according to radiological criteria of bone fusion in craniectomy margins and cerebral protection without gaps or erosions in the skull).

\subsubsection{Secondary Outcome Measures}

These included adverse effects occurred at any time within 12 months of follow up, and usually not required a second operation: epidural hematoma, wound dehiscence and poor cosmetic result.

\subsection{Statistical Analysis}

All analyses were conducted according to an intention to- treat basis. Categorical and continuous outcomes with skewed distributions were analyzed by chi-square test. All analyses were conducted using SPSS for Windows (version 22.0, IBM), and a $\mathrm{p}$ value $<0.05$ was taken as significant.

\section{Results}

A total of 32 patients were included in the study:

\subsection{Age and Gender Distribution of the Studied Patients}

Age and gender distribution of the studied patients is shown in Table 1. Of the 32 patients included in the study, maximum were in the age group of (20 - 30) and $(30-40)$ years, i.e., $31.25 \%$ for each age group $(\mathrm{n}=10)$. Among all the patients $68.75 \%(n=22)$ were males and $31.25 \%(n=10)$ were females, The larger number of male patients in both age groups $(20-30)$ and $(30-40)$ is related to the lifestyle of people in Upper Egypt as males are more susceptible to trauma in daily activities (work, sports, assault from others, ... etc.).

\subsection{Complications Following Cranioplasty}

Complications were found in $10(31.25 \%)$ out of 32 patients. 6 of them were males (18.75\%) and 4 females (12.5\%). Most of them (4 cases 12.5\%) were in age group $(20$ - 30) years. The aetiology of bone defect was trauma in $8(25 \%)$ patients. 6 cases $(18.75 \%)$ out of complicated patients were in artificial material group and 4 cases (12.5\%) in autologous group. 3 cases (9.375\%) were infected, bone resorption was in 2 patients (6.25\%), extradural hematoma in 1 case (3.125\%), wound dehiscence in 1 case (3.125\%) and poor cosmetic result in 3 cases $(9.375 \%)$.

Time of surgical procedure was $>120$ minutes in 5 cases (15.625\%), $60-120$ minutes in $4(12.5 \%)$ cases and $<60$ minutes in one case $(3.125 \%)$. Time interval between craniectomy and cranioplasty was $<12$ weeks in 4 cases (12.5\%), 12 - 24 cases in 2 cases $(6.25 \%)$ and $>24$ weeks in 4 cases $(12.5 \%)$.

Eight (8) cases ( $25 \%$ out of total 32 cases) with traumatic aetiology were complicated. However, 1 case was complicated in each of tumor and spontaneous hemorrhage group. ( $\mathrm{P}$ value is $<0.01$ ) which is statistically significant difference 
showing us that patients with traumatic aetiology is in more risk for developing post cranioplasty complications (Table 2).

\subsection{Complications in Relation to Material Used in Cranioplasty}

The overall complication rate in autologous group was found to be (25\%) (4 cases out of 16), in artificial group 6 cases out of 16 were complicated (37.5\%).

( $\mathrm{P}$ value $<0.025$ ), therefore, there is statistically significant difference between autologous and artificial groups regarding incidence of overall complication. See Table 3.

\subsection{Complications in Each Synthetic Material Used in Cranioplasty}

Titanium mesh was used in total of 8 cases, no cases were infected, 3 cases were found to have poor cosmetic results (37.5\%) and 1 case of wound dehiscense (12.5\%), overall complication rate is $50 \%$ without any statistically significant difference between Titanium mesh and methyl methacrylate (bone cement) which has the same overall complication rate $(50 \%)$. However, when only primary outcome (infection) is considered, methyl methacrylate (bone cement) group has 2 infected cases out of 4 (50\%), while titanium mesh group has no infected cases. See Table 4.

( $\mathrm{P}$ value $<0.01$ ) which is very strong statistically significant difference that methyl methacrylate (bone cement) has very high risk for post operative infection more than Titanium mesh cranioplasty. On the other hand, no complications occurred in 4 cases of Medpor cranioplasty.

Table 1. Age and gender distribution of the studied patients.

\begin{tabular}{|c|c|c|c|c|c|c|}
\hline \multirow{2}{*}{$\begin{array}{c}\text { Age group } \\
(20-30) \text { years }\end{array}$} & \multicolumn{2}{|c|}{ Male } & \multicolumn{2}{|c|}{ Female } & \multicolumn{2}{|c|}{ Total } \\
\hline & 8 & $25 \%$ & 2 & $6.25 \%$ & 10 & $31.95 \%$ \\
\hline$(30-40)$ & 7 & $21.87 \%$ & 3 & $28.125 \%$ & 10 & $31.95 \%$ \\
\hline$(40-50)$ & 2 & $6.25 \%$ & 3 & $28.125 \%$ & 5 & $15.6 \%$ \\
\hline$(50-60)$ & 5 & $15.62 \%$ & 2 & $6.25 \%$ & 7 & $21.9 \%$ \\
\hline Total & 22 & $68.75 \%$ & 10 & $31.25 \%$ & & 32 \\
\hline
\end{tabular}

Table 2. Complications in patients with different aetiology of bone defect.

\begin{tabular}{|c|c|c|c|c|c|c|c|}
\hline \multirow{2}{*}{$\begin{array}{c}\text { Complication } \\
\text { Infection }\end{array}$} & \multicolumn{2}{|c|}{ Trauma } & \multicolumn{2}{|c|}{ Tumor } & \multicolumn{2}{|c|}{ Hemorrhage } & \multirow{2}{*}{$\frac{\text { Total }}{3}$} \\
\hline & 2 & $6.25 \%$ & 0 & 0 & 1 & $3.12 \%$ & \\
\hline Bone resorption & 2 & $6.25 \%$ & 0 & 0 & 0 & 0 & 2 \\
\hline Extradural hematoma & 1 & $3.12 \%$ & 0 & 0 & 0 & 0 & 1 \\
\hline Wound dehiscense & 0 & 0 & 1 & $3.12 \%$ & 0 & 0 & 1 \\
\hline Poor cosmetic result & 3 & $9.37 \%$ & 0 & 0 & 0 & 0 & 3 \\
\hline Total & 8 & $25 \%$ & 1 & $3.12 \%$ & 1 & 3.12 & 10 \\
\hline
\end{tabular}


Table 3. Complications in both autologous and artificial groups.

\begin{tabular}{cccccc}
\hline Complication & & Autologous & Artificial & $\%$ & Total \\
\hline Infection & 1 & $6.25 \%$ & 2 (bone cement) & $12.5 \%$ & 3 \\
Bone resorption & 2 & $12.5 \%$ & 0 & 0 & 2 \\
Extradural hematoma & 1 & $6.25 \%$ & 0 & 0 & 1 \\
Wound dehiscense & 0 & 0 & 1 (Titanium mesh) & $6.25 \%$ & 1 \\
Poor cosmetic result & 0 & 0 & 3 (Titanium mesh) & $18.75 \%$ & 3 \\
Total & 4 & $25 \%$ & 6 & $37.5 \%$ & 10 \\
\hline
\end{tabular}

Table 4. Complications in different artificial materials used in cranioplasty.

\begin{tabular}{|c|c|c|c|c|c|c|c|c|}
\hline \multirow{2}{*}{$\begin{array}{l}\text { Material used } \\
\text { Titanium Mesh }\end{array}$} & \multicolumn{2}{|c|}{ Infection } & \multicolumn{2}{|c|}{$\begin{array}{c}\text { Wound } \\
\text { dehiscense }\end{array}$} & \multicolumn{2}{|c|}{$\begin{array}{c}\text { Poor } \\
\text { cosmetic result }\end{array}$} & \multirow{2}{*}{$\begin{array}{c}\text { Complicated } \\
\text { cases }\end{array}$} & \multirow{2}{*}{$\begin{array}{c}\text { Total } \\
8\end{array}$} \\
\hline & 0 & 0 & 1 & $12.5 \%$ & 3 & $37.5 \%$ & & \\
\hline Bone cement & 2 & $50 \%$ & 0 & 0 & 0 & 0 & 2 & 4 \\
\hline Medpor & 0 & 0 & 0 & 0 & 0 & 0 & 0 & 4 \\
\hline
\end{tabular}

\subsection{Complications in Relation to Time Interval between Craniectomy and Cranioplasty}

Time interval between craniectomy and cranioplasty has very strong statistical significance among each group (autologous versus artificial) with overall complication rate among autologous group $40 \%$ in cases with time interval more than 24 weeks, while complications appear in artificial group only in cases of $<12$ weeks and 12 - 24 weeks interval, the least overall complication rate (20\%) was found in cases with time interval between 12 and 24 weeks between craniectomy and cranioplasty $(\mathrm{P}$ value $<0.01)$. See Table 5 and Table 6 .

\subsection{Complications in Relation to Time of Surgical Procedure}

Overall complication rate was found to be $25 \%$ in surgeries with $<60$ minutes time of procedure, $21.2 \%$ in surgical procedures between 60 and 120 minutes. And $55.55 \%$ in surgical procdures more than 120 minutes. there is no statistically significant difference in complication rate between $<60$ minutes and $60-120$ minutes procedures with ( $\mathrm{P}$ value $>0.25$ ), However, very strong statistically significant difference in overall complication rate when compared to $>120$ minutes surgical procedures with ( $\mathrm{P}$ value $<0.01)$ (Table 7$)$.

\subsection{Cases Presentation}

\subsubsection{Case (1)}

Male patient 35 years old with motor bike accident, the patient had disturbed level of consciousness GCS 8 and his brain CT showed acute subdural hematoma with brain edema compressing the brain (midline shift). Decompressive craniectomy was done and the bone flap was stored subcutaneously in the patient's abdomen. The patient improved clinically and became fully conscious. One 
month later the patient presented by infected abdominal wound with pus discharge. The inflamed bone (osteomyelitis) was extracted and sent for pathology and culture and sensitivity. 6 months later ( $>24$ weeks) the patient underwent cranioplasty with Titanium mesh. See Figure 1.

Based on our observations in (Results) and analysis in (Discussion): this case had at least two risk factors for infection: traumatic aetiology of bone defect and long time (>120 minutes) surgical procedure for decompressive craniectomy.

Also, long time interval between craniectomy and cranioplasty ( $>24$ weeks) increased the risk of developing post cranioplasty extradural hematoma.

Table 5. Incidence of overall complications in both autologous and artificial groups in relation to time interval between craniectomy and cranioplasty.

\begin{tabular}{|c|c|c|c|c|c|c|c|c|c|}
\hline \multirow{2}{*}{$\begin{array}{c}\begin{array}{c}\text { Material } \\
\text { used }\end{array} \\
\text { Autologous }\end{array}$} & \multirow{2}{*}{$\begin{array}{c}<12 \\
\text { weeks } \\
1\end{array}$} & \multicolumn{2}{|c|}{ Complicated } & \multirow{2}{*}{$\begin{array}{c}12-24 \\
\text { week } \\
5\end{array}$} & \multicolumn{2}{|c|}{ Complicated } & \multirow{2}{*}{$\begin{array}{c}>24 \\
\text { weeks } \\
10\end{array}$} & \multicolumn{2}{|c|}{ Complicated } \\
\hline & & 0 & 0 & & 0 & 0 & & 4 & $40 \%$ \\
\hline Artificial & 9 & 4 & $44 \%$ & 5 & 2 & $40 \%$ & 2 & 0 & 0 \\
\hline Total & 10 & 4 & $40 \%$ & 10 & 2 & $20 \%$ & 12 & 4 & $33 \%$ \\
\hline
\end{tabular}

Table 6. Complications in relation to time interval between craniectomy and cranioplasty $(4 / 10,2 / 10 \ldots$ etc.: total number of complicated cases/total number of cases in each group).

\begin{tabular}{|c|c|c|c|c|c|c|c|c|}
\hline \multirow{2}{*}{$\begin{array}{c}\text { Complication } \\
\text { Infection }\end{array}$} & \multicolumn{2}{|c|}{$<12$ weeks } & \multicolumn{2}{|c|}{12 - 24 weeks } & \multicolumn{2}{|c|}{$>24$ weeks } & \multirow{2}{*}{$\frac{\text { Total }}{3}$} & \multirow{2}{*}{$\begin{array}{c}\% \\
9.375 \%\end{array}$} \\
\hline & 2 & $20 \%$ & 0 & 0 & 1 & $8.3 \%$ & & \\
\hline Bone resorption & 0 & 0 & 0 & 0 & 2 & $16.6 \%$ & 2 & $6.25 \%$ \\
\hline $\begin{array}{l}\text { Extradural } \\
\text { hematoma }\end{array}$ & 0 & 0 & 0 & 0 & 1 & $8.3 \%$ & 1 & $3.125 \%$ \\
\hline $\begin{array}{c}\text { Wound } \\
\text { dehiscence }\end{array}$ & 0 & 0 & 1 & $10 \%$ & 0 & 0 & 1 & $3.125 \%$ \\
\hline $\begin{array}{c}\text { Poor cosmetic } \\
\text { result }\end{array}$ & 2 & $20 \%$ & 1 & $10 \%$ & 0 & 0 & 3 & $9.375 \%$ \\
\hline Total & $4 / 10$ & $40 \%$ & $2 / 10$ & $20 \%$ & $4 / 12$ & $33.33 \%$ & $10 / 32$ & $31.25 \%$ \\
\hline
\end{tabular}

Table 7. Complications in relation to time of surgical procedure.

\begin{tabular}{|c|c|c|c|c|c|c|c|c|}
\hline \multirow{2}{*}{$\begin{array}{c}\text { Complication } \\
\text { Infection }\end{array}$} & \multicolumn{2}{|c|}{$<60$ mins } & \multicolumn{2}{|c|}{$60-120$ mins } & \multicolumn{2}{|c|}{$>120 \mathrm{mins}$} & \multicolumn{2}{|c|}{ Total } \\
\hline & 0 & 0 & 0 & 0 & 3 & $33.33 \%$ & 3 & $3.125 \%$ \\
\hline Bone resorption & 0 & 0 & 2 & $10.5 \%$ & 0 & 0 & 2 & $6.25 \%$ \\
\hline $\begin{array}{l}\text { Extradural } \\
\text { hematoma }\end{array}$ & 1 & $25 \%$ & 0 & 0 & 0 & 0 & 1 & $3.125 \%$ \\
\hline $\begin{array}{c}\text { Wound } \\
\text { dehiscence }\end{array}$ & 0 & 0 & 1 & $5.26 \%$ & 0 & 0 & 1 & $3.125 \%$ \\
\hline $\begin{array}{c}\text { Poor } \\
\text { cosmtic result }\end{array}$ & 0 & 0 & 1 & $5.26 \%$ & 2 & $22.22 \%$ & 3 & $9.375 \%$ \\
\hline Total & $1 / 4$ & $25 \%$ & $4 / 19$ & $21.2 \%$ & $5 / 9$ & $55.55 \%$ & 10 & $31.25 \%$ \\
\hline
\end{tabular}



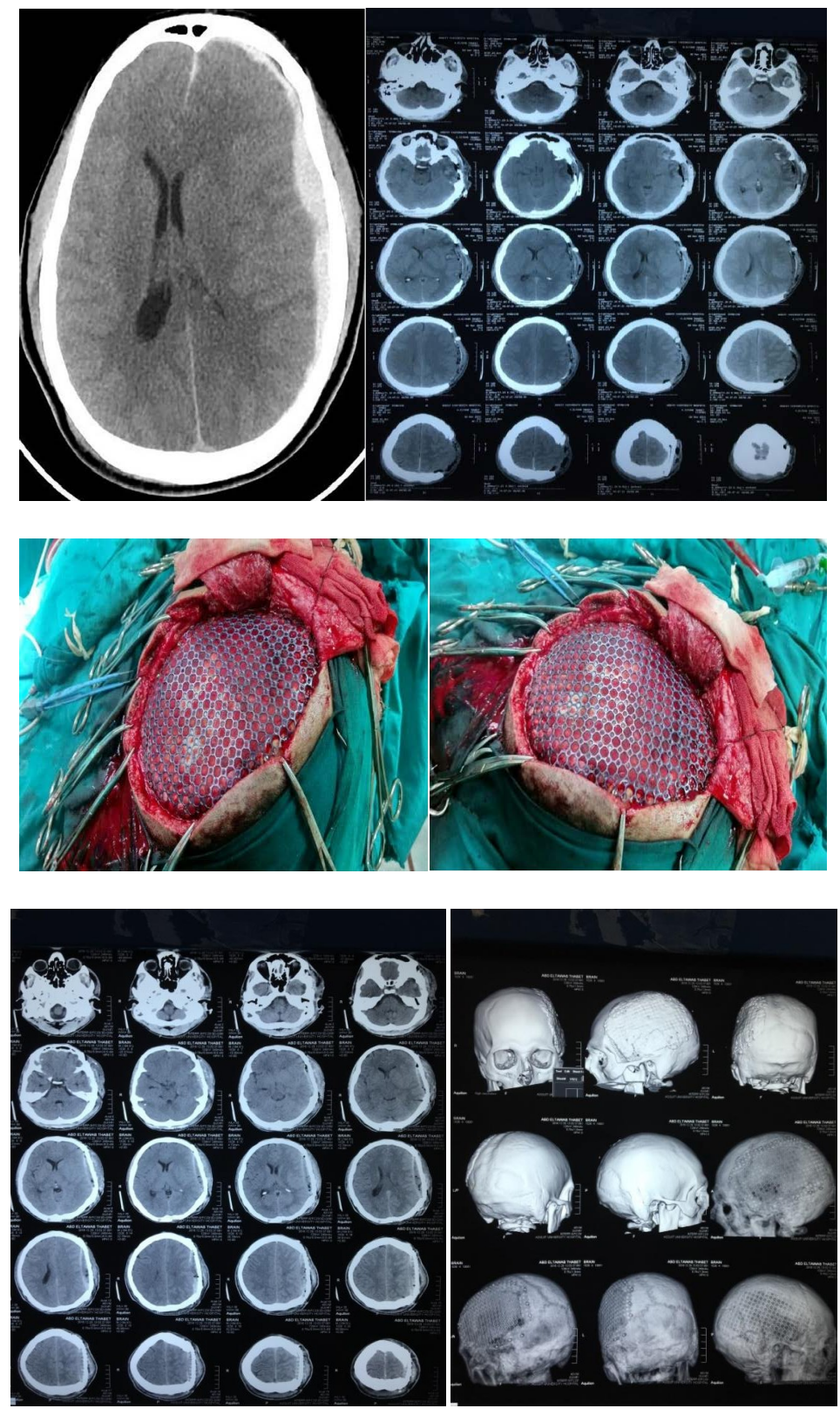

Figure 1. Pre, intra and post operative images of the patient with Titanium mesh cranioplasty.

\subsubsection{Case (2)}

Male patient 22 years old presented with confusion and right sided hemi convulsions. The patient has history of head trauma one month before this presentation and he didn't seek medical advice. CT brain was done, sharp bone specule with underlying brain abscess was found. Surgical excision was done with post operative bone defect was measured and reconstruction with bone cement was done later. See Figure 2.

Bone cement has a high risk of infection and are not strong as titanium. However, it gives better cosmetic results in many cases than titanium, as we mentioned in (Results) and the analysis in (Discussion). 

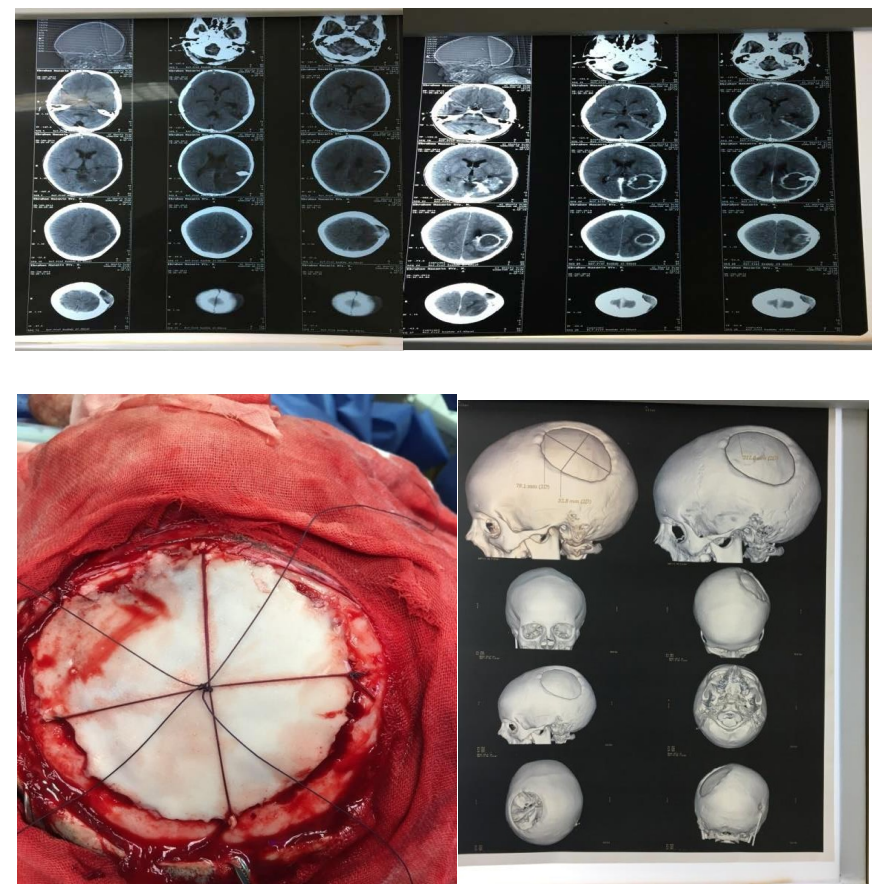

Figure 2. Cranioplasty by bone cement.

\subsubsection{Case (3)}

55 years old female patient with fibrous dysplasia of the skull bone on left frontal area. The bone was excised and later on a cranioplasty with Medpor was done with excellent results functionally and cosmetically (Figure 3 ).

\subsubsection{Case (4)}

Female 53 years presented to emergency department with disturbed conscious level and right sided weakness without history of trauma. CT was done and shows acute subdural hmatoma on left side. Decompressive craniectomy was done.

Later, the patient was prepared to autologous bone cranioplasty (Figure 4).

\section{Discussion}

This study represents prospective randomized clinical trial comparing between autogenous bone cranioplasty and synthetic materials that are most frequently used in cranioplasty (Titanium mesh, methyl methacrylate and Medpor). The hypothesis upon which the trial was based was that autologous bone cranioplasty has less risk of post operative complications than using artificial (synthetic) materials.

At the initial predetermined 12 months of follow up, the results showed tendency to support this hypothesis, with statistical significant difference regarding overall complication rate between autologous and artificial cranioplasty. Overall complication rate was $31.25 \%$, which is slightly less than reported by Gooch et al., who had complication rate of $33 \%$ [8]. Complication rate in autologous group was $25 \%$ comparing to $37.5 \%$ in artificial group. And this would seem to 
favour the use of autologous bone over artificial (synthetic) materials. Klinger et al. reported parallel findings regarding complications in autologous versus artificial cranioplasty [9], whereas Reddy et al. [10] observed a higher infection rate among patients with alloplast reconstruction. This finding is in accordance to this study. However, there are a number of issues that require consideration:

1) Age of the patient is an important factor in decision making about autologous versus artificial cranioplasty, the results show that cases of bone resorption in autologous cranioplasty ( 2 cases) are all below 40 years of age, thus the study supports the use of artificial (synthetic materials) in patients between 20 and 40 years of age, what remains to be established is the ideal material in the pediatric population, which is out of the scope of this study.

2) The aetiology of the bone defect which was classified in this study as (trauma, tumor and spontaneous hemorrhage) showed statistically significant difference regarding overall complication rate in both autologous and artificial groups. Based on our results, Trauma as a cause of bone defect has more risk for post operative complications of cranioplasty. However, other causes of bone defect such as infection (osteomyelitis) or congenital causes are out of the scope of this study.

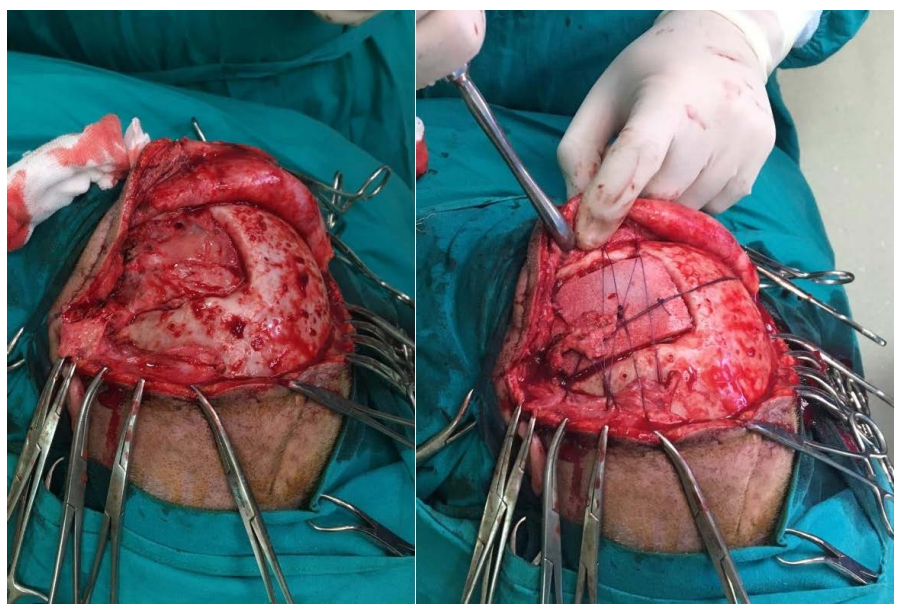

Figure 3. Intraoperative during Medporcranioplasty.

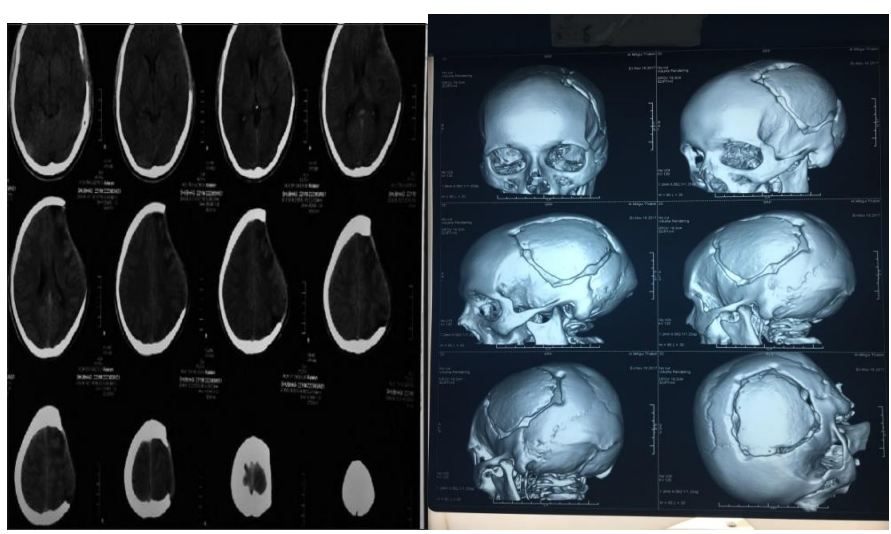

Figure 4. Autologous bone Cranioplasty. 
3) Comparing overall complication rate between males and females, females were found to have higher rate ( $40 \%$ versus $27.27 \%$ ) with strong statistically significant difference, and this may be related to other factors that promote infection in female cases, as low Glasgcow coma scale (score $<10$ ) at initial presentation in some cases and long hospital stay before beginning of cranioplasty surgery.

Infection was recorded in 3 cases out of 32 (9.375\%), which is somewhat consistent with the reported rate of infection, $7 \%-22 \%$ [11]. Infection in artificial group is much higher (12.5\%) than autologous group (6.25\%) with statistically significant difference. With larger sample size, this difference might be not statistically significant leading to the result that the choice of graft material (autologous versus artificial) do not seem to influence the rate of infections [12]. Yadla et al. concluded that implant material has no effect on the infection rate or overall complication rate [13]. Other important factors are also associated with increased risk for post operative infection: aetiology of bone defect, time of surgical procedure and time interval between craniectomy and cranioplasty.

Two cases (6.25\%) had traumatic aetiology of bone defect and were complicated with wound infection after cranioplasty. This rate is higher than infection in tumor or spontaneous hemorrhage group of patients. Klinger DR et al. reported that $(8.2 \%)$ of patients had traumatic brain injury and were complicated by post cranioplasty infection, which is slightly higher rate than our study. And this was thought to be due to complexity of initial injury: penetrating injuries, compound fractures, dirty wounds and involvement of frontal air sinus. [9]

All 3 cases of infection in the study had time of surgical procedure $>120 \mathrm{mi}-$ nutes (33.33\%) out of total 9 cases had this time procedure. And this result significantly showed the effect of time consuming during surgery in preparation of bone cement and titanium mesh to be well fitted to the skull of the patient. The handling of implants can make maintenance of sterility difficult specially in inexperienced hands, and this may result in a higher infection rate after cranioplasty. Al-Shalchy conducted a study in which $90 \%$ of the patients were operated within 1 - 3 hours, which is somewhat in accordance to this study [14]. Complications were noted in (15.25\%) of the patients and wound infection/dehiscence $(6.78 \%)$ was the most common complication encountered.

Walcott et al. in their study reported that wound infection (12.13\%) was the most common complication following cranioplasty. They had a net complication rate of $(23.85 \%)$, which is somewhat in accordance to this study [15]. Also, the results showed that infection is related significantly to time interval between craniectomy and cranioplasty, with $20 \%$ infection rate in early cranioplasty $(<12$ weeks) versus $8.3 \%$ in late cranioplasty ( $>24$ weeks). Im et al. reported a non-significant trend toward increased risk of post operative infection with early cranioplasty, and the work of Thavarajah et al. indicates that cranioplasty should be postponed as late as 6 months to minimize the risk [16] [17]. However, in a meta analysis of 18 articles, Yadla et al. found no difference in the infection rates 
between early ( $<3$ months) and late ( $>3$ months) surgery [13], other later studies also showed the same [12] [18].

The reported rates of bone resorption vary greatly in the literature, ranging from $1.4 \%$ to $22.8 \%$ [9] [19]. In this study, 2 cases out of 32 (6.25\%) developed clinical and radiological signs of bone necrosis. And as previously mentioned, both are in age groups $(20-30)$ and $(30-40)$ years of age.

The results show significant relation between bone resorption and "delayed" cranioplasty. In fact, many studies fail to demonstrate an association between time of cranioplasty and risk of bone flap resorption [19] [20]. Generally, preservation of bone flap in subcutaneous abdominal pocket has the advantage of supplying nutrition to the autologous graft [21]. There are examples of new bone formation within the bone flap in this method [22]. However, cases in our study showed remodeling during subcutaneous abdominal storage with gradual loss of volume, and this can be explained partially by fragmentation of bone flap during the initial trauma which was the aetiology of bone defect in both two cases. Fragmentation showed a clear correlation with the risk of bone flap resorption because it could potentially result in severe disruption of the blood circulation, disturbing angiogenesis and leading to nutritional deficit of the bone flap. This is supported by results of many other studies [20] [23].

Extradural hematoma was noted in 1 case $(3.125 \%)$ and was managed conservatively by only follow up clinically and radiologically. Reported rates for hematomas vary from $1.8 \%$ to $12.25 \%$ [8]. As previously mentioned, several risk factors are responsible for the development of post operative hematomas. The results in this study showed statistically significant relation between development of post operative extradural hematoma and "delayed cranioplasty" with time interval $>24$ weeks between craniectomy and cranioplasty, also there was statistically significant relation with relatively short time of surgical procedure $<60$ minutes. Some authors have advanced the idea of early cranioplasty after decompressive craniectomy to minimize rate of post operative extradural hematoma [24].

Early cranioplasty performed before massive scar formation reduces operative time by facilitating soft tissue dissection. Liang et al. reported that early cranioplasty was safe and improve patient's neurological function and prognosis. In addition, early cranioplasty has an advantage in dissection during surgery [25].

Wound dehiscence without concurrent infection was observed in 1 case (3.125\%) of the patients. only minor skin revision was done to this case. Complictions affecting skin flaps after cranioplasty seem to occupy no space in major authors' experience. In the work of Honeybal and Ho [26] no cutaneous problems were mentioned. Also in the work of Gooch et al., wound complications were not mentioned at all [27].

Dehiscence are presumed to be easy to deal with. This is true only if observed and treated promptly. "Closing the skin" is rarely the main problem in these patients. The decision whether or not to remove a cranial prosthesis is difficult and trouble shooting. Removal of cranioplasty flap might expose even patients in 
good clinical conditions to deterioration especially in patients with shunts contralateral to cranioplasty which is quietly a common condition. In these cases, there is very high risk for subdural hygroma or hematoma and sinking flap syndrome. So, accurate evaluation of the least possible harm should always be performed.

The psychological effect produced by a malformed appearance of a bony defect may present a need for cranioplasty regardless of the size. Burr hole defects are generally asymptomatic; however, if they are situated in the frontal region, the correction is often necessary for cosmtic reasons [28]. In this study, 3 cases (approximately 19\% out of 16) of artificial cranioplasty group had poor cosmetic result. Which is statistically significant that using artificial bone substituets has more risk of poor cosmetic result than using autologous bone, this is in accordance with results that were found by Al-Shalchy AK [14], where 20\% requiring another surgery due to poor cosmetic result, and this was thought to be due to partial resorption of autologous bone after implantation. poor cosmetic result in titanium mesh cranioplasty might be due to flattening occurred in the head contour especially in large defects and the mesh has been stretched across it, compromising the convexity in its shape.

There were 3 synthetic materials used as substitutes of autologous bone in this study: Titanium mesh, bone cement (PMMA) and Medpor.

Titanium mesh overall complication rate was $50 \%$ (12.5\% wound dehiscence and $37.5 \%$ poor cosmetic result). Bone cement (PMMA) had also an overall complication rate of $50 \%$. However, this rate of $50 \%$ was due to infection ( 2 cases out of 4) while titanium mesh group had no infected cases. Bone cement had statistically significant difference regarding the risk of post operative infection rate. On the other hand, no complications occurred in 4 cases of Medporcranioplasty.

The decision for one of the many available materials often depends on the surgeon's preference, experience and costs.

Because of its good biocompatibility and low costs, PMMA is frequently used and was regarded as the material of choice by many authors [29].

However, the use of methyl methacrylate has many complications including an exothermic reactions produced intraoperatively during preparation which may result in local tissue damage, release of a toxic monomer that has been implicated in local and systemic reactions, fracture of the implant and a significant rate of infection [30].

Titanium mesh is easily moldable and ready to apply over the cranial defect once it is exposed. It is easy to handle and adapt to the desired shape and contour intraoperatively. Although not as rigid as bone itself, titanium mesh is sufficiently protective to the cranial contents [31]. Titanium mesh also can be used in the frontal region. The forehead being the dominant and the most noticeable part of the face, cranioplasty of this region is cosmetically and functionally challenging. Titanium mesh is better than autologous bone in repairing defects of the frontal region [32]. 
Porous polyethylene is a highly inert material and provides a consistently benign clinical response over many years of use in humans [33]. Medpor has been used for coverage of small and medium sized cranial defects $\left(<8 \mathrm{~cm}^{2}\right)$ in different locations. This experience suggests that medpor is safe, cosmetically equivalent alternative to methyl methacrylate cranioplasty, with the advantage of lower infection rate and shorter operative time. It is not designed to function as a structural support material, it is recommended only for non load bearing small and medium sized defects, and may in fact prove to be specially useful for implantation adjacent to nasal sinuses in skull base and craniofacial reconstruction [34].

\section{Conclusions}

- Cranioplasty carries a high risk of post operative complications; Infection and bone resorption are the most common.

- Infection was found to be associated significantly to type of the material used in cranioplasty "bone cement is the most significant" and time interval between craniectomy and cranioplasty "infection is associated with early cranioplasty".

- Bone flap resorption is a key complication after cranioplasty using autologous bone flaps. Young age and bone fragmentation are risk factors for reoperation. So, a primary synthetic implant is recommended in cases with fragmented bone flap, delayed time of cranioplasty ( $>3$ months) or in patients younger than 30 years of age.

- Methyl methacrylate (bone cement) is cheaper than titanium mesh and is easy to contour and remodel giving a better cosmetic result, but it carries higher risk of infection and is less protective to the cranial contents.

- Titanium mesh has good protective function and less risk of infection than bone cement; cosmetic result is acceptable in most cases and can be improved according to the surgeon's experience.

- Medpor has excellent results functionally and cosmetically especially in small and medium sized skull bone defects and in craniofacial reconstruction. However, high cost limits its use especially in poor countries.

\section{Conflicts of Interest}

The authors declare no conflicts of interest regarding the publication of this paper.

\section{References}

[1] Aydin, S., Kucukyuruk, B., Abuzayed, B. and Sanus, G.Z. (2011) Cranioplasty: Review of Materials and Techniques. Journal of Neurosciences in Rural Practice, 2, 162-167. https://doi.org/10.4103/0976-3147.83584

[2] Shah, A.M., Jung, H. and Skirboll, S. (2014) Materials Used in Cranioplasty: A History and Analysis. Neurosurgical Focus, 36, E19. 
https://doi.org/10.3171/2014.2.FOCUS13561

[3] Winkler, P.A., Stummer, W., Linke, R., et al. (2000) Influence of Cranioplasty on Postural Blood Flow Regulation, Cerebrovascular Reserve Capacity, and Cerebral Glucose Metabolism. Journal of Neurosurgery, 93, 53-61.

https://doi.org/10.3171/jns.2000.93.1.0053

[4] Piitulainen, J.M. and Kauko, T. (2015) Outcomes of Cranioplasty with Synthetic Materials and Autologous Bone Grafts. World Neurosurgery, 83, 708-714. https://doi.org/10.1016/j.wneu.2015.01.014

[5] Quah, P.L., Low, H.L., Wilson, M.H., Bimpis, A., Nga, V.D., Lwin, S., et al. (2016) Is There an Optimal Time for Performing Craniplasties? World Neurosurgery, 94, 13-17. https://doi.org/10.1016/j.wneu.2016.06.081

[6] Zins, J.E., Langevin, C.J. and Nasir, S. (2010) Controversies in Skull Reconstruction. Journal of Craniofacial Surgery, 21, 1755-1760. https://doi.org/10.1097/SCS.0b013e3181c34675

[7] Beekmans, S.J., Don Griot, J.P. and Mulder, J.W. (2007) Split Rib Cranioplasty for Aplasia Cutis Congenita and Traumatic Skull Defects: More than 30 Years of Follow-Up. Journal of Craniofacial Surgery, 18, 594-597. https://doi.org/10.1097/scs.0b013e3180576f44

[8] Inamasu, J., Kuramae, T. and Nakatsukasa, M. (2010) Does Difference in the Storage Method of Bone Flaps after Decompressive Craniectomy Affect the Incidenceof Surgical Site Infection after Cranioplasty? Comparison between Subcutaneous Pocket and Cryopreservation. The Journal of Trauma Injury Infection and Critical Care, 68, 183-187. https://doi.org/10.1097/TA.0b013e3181c45384

[9] Klinger, D.R., Madden, C., Beshay, J., White, J., Gambrell, K. and Rickert, K. (2013) Autologous and Acrylic Cranioplasty: A Review of 10 Years and 258 Cases. World Neurosurgery, 82, e525-e530. https://doi.org/10.1016/j.wneu.2013.08.005

[10] Reddy, S., Khalifin, S., Flores, J.M., Belllamy, J. and Manson, P.N. (2014) Clinical Outcomes in Cranioplasty: Risk Factors and Choice of Reconstructive Material. Plastic and Reconstructive Surgery, 133, 864-873. https://doi.org/10.1097/PRS.0000000000000013

[11] Lee, L., Ker, J., Quah, B.L., Chou, N., Choy, D. and Yeo, T.T. (2013) A Retrospective Analysis and Review of an Institution's Experience with the Complications of Cranioplasty. British Journal of Neurosurgery, 27, 629-635. https://doi.org/10.3109/02688697.2013.815313

[12] Josan, V.A., Sgouros, S., Walsh, A.R., Dover, M.S., Nishikawa, H. and Hockley, A.D. (2005) Cranioplasty in Children. Child s Nervous System, 21, 200-204. https://doi.org/10.1007/s00381-004-1068-2

[13] Yadla, S., Campbell, P.G., Chitale, R., Maltenfort, M.G., Jabbour, P. and Sharan, A.D. (2011) Effect of Early Surgery, Material, and Method of Flap Preservation on Cranioplasty Infections: A Systematic Review. Neurosurgery, 68, 1124-1130. https://doi.org/10.1227/NEU.0b013e31820a5470

[14] Al-Shalchy, A.K. (2010) Cranioplasty the Use Synthetic (Acrylic) or Autograft. Journal of the Faculty of Medicine Baghdad, 52, 30-31.

[15] Walcott, B.P., Kwon, C.-S., Sheth, S., Fehnel, C.R., Koffie, R.M., Asaad, W.F., et al. (2013) Predictors of Cranioplasty Complications in Stroke and Trauma Patients. Journal of Neurosurgery, 118, 757-762. https://doi.org/10.3171/2013.1.JNS121626

[16] Im, S.H., Jang, D.K., Han, Y.M., Kim, J.T., Chung, D.S. and Park, Y.S. (2012) Long-Term Incidence and Predicting Factors of Cranioplasty Infection after De- 
compressive Craniectomy. Journal of Korean Neurosurgical Society, 52, 396-403. https://doi.org/10.3340/jkns.2012.52.4.396

[17] Thavarajah, D., Lacy, P.D., Hussien, A. and Sugar, A. (2012) The Minimum Time for Cranioplasty Insertion from Craniectomy Is Six Months to Reduce Risk of Infection-A Case Series of 82 Patients. British Journal of Neurosurgery, 26, 78-80. https://doi.org/10.3109/02688697.2011.603850

[18] Wachter, D., Reineke, K., Behm, T. and Rohde, V. (2013) Cranioplasty after Decompressive Hemicraniectomy: Underestimated Surgery-Associated Complications? Clinical Neurology and Neurosurgery, 115, 1293-1297. https://doi.org/10.1016/j.clineuro.2012.12.002

[19] Schoekler, B. and Trummer, M. (2014) Prediction Parameters of Bone Flap Resorption Following Cranioplasty with Autologous Bone. Clinical Neurology and Neurosurgery, 120, 64-67. https://doi.org/10.1016/j.clineuro.2014.02.014

[20] Dunish, P., Walter, J., Sakr, Y. and Kalff, R. (2013) Risk Factors of Aseptic Boneresorption: A Study after Autologous Bone Flap Reinsertion Due to Decompressive Craniotomy. Journal of Neurosurgery, 118, 1141-1147.

https://doi.org/10.3171/2013.1.JNS12860

[21] Shoakazemi, A., Flannery, T. and McConnel, R.S. (2009) Long Term Outcome of Subcutaneously Preserved Autologous Cranioplasty. Neurosurgery, 65, 505-510. https://doi.org/10.1227/01.NEU.0000350870.69891.86

[22] Movassaghi, K., Ver Halen, J., Ganchi, P., Amin-Hanjani, S., Mesa, J. and Yaremchuk, M.J. (2006) Cranioplastywiyh Subcutaneously Preserved Autologous Bone Grafts. Plastic and Reconstructive Surgery, 117, 202-206. https://doi.org/10.1097/01.prs.0000187152.48402.17

[23] Bowers, C.A., Riva-Cambrin, J., Hertzler, D.A. and Walker, M.L. (2013) Risk Factors and Rates of Bone Flap Resorption in Pediatric Patients after Decompressivecraniectomy for Traumatic Brain Injury. Journal of Neurosurgery: Pediatrics, 11, 526-532. https://doi.org/10.3171/2013.1.PEDS12483

[24] Chun, H.J. and Yi, H.J. (2011) Efficacy and Safety of Early Cranioplasty, at Least within 1 Month. Journal of Craniofacial Surgery, 22, 203-207. https://doi.org/10.1097/SCS.0b013e3181f753bd

[25] Liang, W., et al. (2007) Cranioplasty of Large Cranial Defect at an Early Stage after Decompressive Craniectomy Performed for Severe Head Trauma. Journal of Craniofacial Surgery, 18, 526-532. https://doi.org/10.1097/scs.0b013e3180534348

[26] Honeybull, S. and Ho, K.M. (2012) How "Successful” Is Calvarial Reconstruction Using Frozen Autologous Bone? Plastic and Reconstructive Surgery, 130, 1110-1117. https://doi.org/10.1097/PRS.0b013e318267d4de

[27] Gooch, M.R., Gin, G.E., Kenning, T.J. and German, J.W. (2009) Complications of Cranioplasty Following Decompressive Craniectomy: Analysis of 62 Cases. Neurosurgical Focus, 26, E9. https://doi.org/10.3171/2009.3.FOCUS0962

[28] Grantham, E.G. and Landis, H.P. (1948) Cranioplasty and the Post Traumatic Syndrome. Journal of Neurosurgery, 5, 19-22. https://doi.org/10.3171/jns.1948.5.1.0019

[29] Moreira-Gonalez, A., Jackson, I.T., Miyawaka, T., Baqrakat, K. and DiNick, V. (2003) Clinical Outcome in Cranioplasty: Critical Review in Long Term Follow up. Journal of Craniofacial Surgery, 14, 144-153. https://doi.org/10.1097/00001665-200303000-00003

[30] Goiato, M.C., Anchieta, R.B., Pita, M.S. and dos santos, D.M. (2009) Reconstruction of Skull Defects: Currently Available Materials. Journal of Craniofacial Surgery, 20, 
1512-1518. https://doi.org/10.1097/SCS.0b013e3181b09b9a

[31] Wallace, R.D., Craig, M.D. and Konofaos, P. (2015) Comparison of Autogenous and Alloplastic Cranioplasty Materials Following Impact Testing. Journal of Craniofacial Surgery, 26, 1551-1557. https://doi.org/10.1097/SCS.0000000000001882

[32] Kuttenberger, J.J. and Hardt, N. (2001) Long-Term Results Following Reconstruction of Craniofacial Defects with Titanium Micromesh Systems. Journal of Cranio-Maxillofacial Surgery, 29, 75-81. https://doi.org/10.1054/jcms.2001.0197

[33] Duman, H., Deveci, M., Uygur, F. and Sengezer, M. (1999) Reconstruction of Contour and Anterior Wall Defects of Frontal Bone with Porous Polyethylene Implant. Journal of Cranio-Maxillofacial Surgery, 27, 289-301. https://doi.org/10.1054/jcms.1999.0902

[34] Romano, J.J., Iliff, N.T. and Manson, P.N. (1993) Use of Medpor Porous Polyethelene Implants in 140 Patients with Facial Fractures. Journal of Craniofacial Surgery, 4, 142-147. https://doi.org/10.1097/00001665-199307000-00007 